\title{
Study on the Influence of the Number of Expanded-plate on the Soil Failure State of the Concrete Expanded-plate Pile Under Horizontal Force
}

\author{
Yongmei Qian ${ }^{1,}$,, Xiaozhou Li ${ }^{1, b}$, Zixuan Huang ${ }^{1, c}$ \\ ${ }^{1}$ No. 5088, Xincheng Street, Changchun City, Jinlin Province, China

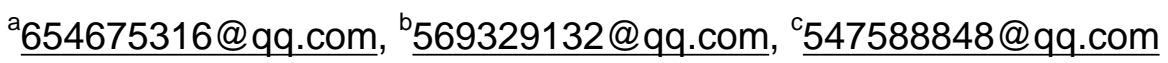

\begin{abstract}
Keywords: The concrete expanded-plate pile, bearing expanded-plate, number, horizontal force, failure state

Abstract: In this paper, the influence of the number of bearing expanded-plate on the concrete expanded-plate pile is studied under horizontal force. Through the ANSYS software, the calculation model is established and analyzed on the basis of the comparison of the straight hole pile with the same length and the same diameter.Then the influence of the number of bearing expanded-plate on the failure state of the soil around the pile under horizontal load is studied and the reasonable number of bearing expanded-plate is determined which provides the theoretical basis for the design and popularization of the concrete expanded-plate pile.
\end{abstract}

\section{Introduction}

In civil engineering, the pile foundation can be used to bear the pressure, uplift force and horizontal force of the three forms of load. With the development of underground space, port engineering, marine engineering and the increase of engineering water depth the horizontal bearing capacity of pile has attracted much attention and has become an important control factor. According to the current research it has been a perfect theoretical and experimental study on the bearing capacity and soil failure of the concrete expanded-plate pile under vertical force at home and abroad. But the influence of horizontal load on the performance of the concrete expanded-plate pile and the failure state of soil around pile is still in the initial stage. The experimental data are few. There is no specific method to calculate horizontal bearing capacity of the pile. And there are few technical specifications about it which can not provide the theoretical basis for the design. Therefore, all these factors have affected its application in engineering.

There are many factors affecting the bearing capacity of concrete expanded-plate pile under horizontal force. In terms of expanded-plate according to the study of domestic and overseas shows that the bearing expanded-plate has a significant influence on the bearing capacity of concrete expanded-plate pile.For example, Qian Deling and others have carried on some research on the bearing mechanism, compaction effect, load transfer characteristics and dissipation of pore water pressure [1]. Research shows that most of the load exceeding the limit load of $60 \%$ is carried by the bearing expanded-plate. According to study of the influence of the bearing capacity of concrete expanded-plate piles under vertical force by Qian Yongmei and Wang Xihui shows that the more the expanded-plate the higher the resistance at the end of the expanded-plate and the higher the bearing capacity of the single pile. The reasonable number of expanded-plate is 1-3[2]. The main factors are as follows: diameter, slope angle, position, spacing and quantity. On the basis of the research on the bearing capacity of concrete expanded-plate pile under vertical and the method of soil failure by Professor Yin Xinsheng and Professor Qian Yongmei, et al. [3,4,5], in this paper, under the same load the influence of the displacement change of the soil around the pile in different expanded-plate number and maximum horizontal displacement-load curve of pile head are studied by controlling a single variable and finite element numerical simulation.Qualitatively analyze the effect of expanded-plate number on the bearing capacity of concrete expanded-plate pile under horizontal force and determine the reasonable number of expanded-plate so as to meet the further needs of engineering design and construction. 


\section{Organization of the Text}

Material Parameter. The finite element model is established by ANSYS. The simulation and analysis of the concrete expanded-plate pile under horizontal load are carried out.The pile-soil model adopts half space symmetrical system. In order to ensure the accuracy of calculation the soil around the pile should have a large enough range that the radial of the pile is $14000 \mathrm{~mm}$ and the thickness of the subsoil of the pile is $4000 \mathrm{~mm}$. The pile is perpendicular to the earth. The pile-soil model has two kinds of materials, namely, concrete and undisturbed soil. Different constitutive models and model parameters are chosen for the two materials, as shown in Table 1.

Table 1 Material Parameter

\begin{tabular}{|c|c|c|c|c|c|c|c|}
\hline Material & $\begin{array}{c}\text { density } \\
\left(\mathrm{t} / \mathrm{mm}^{3}\right)\end{array}$ & $\begin{array}{c}\text { Modulus of } \\
\text { elasticity E } \\
(\mathrm{Mp} a)\end{array}$ & $\begin{array}{c}\text { Poisson } \\
\text { ratio } \mu\end{array}$ & $\begin{array}{c}\text { Cohesion } \\
(\mathrm{M} p a)\end{array}$ & $\begin{array}{c}\text { Friction } \\
\text { angle } \\
\left({ }^{\circ}\right)\end{array}$ & $\begin{array}{c}\text { Expansion } \\
\text { angle }\left({ }^{\circ}\right)\end{array}$ & $\begin{array}{c}\text { Pile-soil } \\
\text { friction } \\
\text { coefficient }\end{array}$ \\
\hline Concrete & $2.5 e-9$ & $3.0 \mathrm{e} 4$ & 0.2 & -- & -- & -- & 0.4 \\
\hline Clay & $1.8 \mathrm{e}-9$ & 25 & 0.3 & 0.017 .4 & 18.29 & 18.29 & 0.4 \\
\hline
\end{tabular}

Model Size. According to the basic requirements of the actual Engineering pile the main pile diameter is $\mathrm{d}=500 \mathrm{~mm}$, the pile length is $\mathrm{L}=11100 \mathrm{~mm}$, the diameter of the expanded-plate is $\mathrm{D}=1500 \mathrm{~mm}$ and the form of bearing expanded-plate is the ordinary double slope type. The calculation model is shown in Fig. 1. Note: $\mathrm{L}$ is the length of the pile, $\mathrm{d}$ is the diameter of the pile, $\mathrm{D}$ is the diameter of expanded-plate, $\mathrm{h}$ is high of expanded-plate, $\mathrm{R}$ is extension length of expanded-plate, $\mathrm{S}$ is net distance of expanded-plates and the reasonable value is $4 \mathrm{R}(2000 \mathrm{~mm})$, La is the distance from the top of the pile to its first expanded-plate, $\theta$ is slope angle. $\mathrm{N}$ is expanded-plates number. The specific model pile size is shown in Table 2 .

Based on the properties of soil layers and previous research that the bearing expanded-plate can exert the capacity of resisting horizontal load when it is installed in the shallower soil layer. The first bearing expanded-plate is arranged at the top of the pile at the distance of $1500 \mathrm{~mm}$. When the other parameters unchanged the plate spacing is $2000 \mathrm{~mm}$ which in turn increases the number of expanded-plate to set up the model of $\mathrm{CP} 1, \mathrm{CP} 2, \mathrm{CP} 3, \mathrm{CP} 4$ and the straight pile model numbers $\mathrm{CNP} 0$. As shown in Fig. 2.

Table 2 Model pile size

\begin{tabular}{|c|c|c|c|c|c|c|c|c|}
\hline number & $\begin{array}{c}\mathrm{d} \\
(\mathrm{mm})\end{array}$ & $\begin{array}{c}\mathrm{D} \\
(\mathrm{mm})\end{array}$ & $\begin{array}{c}\mathrm{h} \\
(\mathrm{mm})\end{array}$ & $\begin{array}{c}\theta \\
\left({ }^{\circ}\right)\end{array}$ & $\begin{array}{c}\mathrm{L} \\
(\mathrm{mm})\end{array}$ & $\begin{array}{c}\mathrm{S} \\
(\mathrm{nhm})\end{array}$ & $\mathrm{N}$ \\
\hline $\mathrm{CP} 0$ & 500 & - & - & - & 11100 & - & - & 0 \\
\hline $\mathrm{CP} 1$ & 500 & 1500 & 700 & 35 & 11100 & 1500 & 2000 & 1 \\
\hline $\mathrm{CP} 2$ & 500 & 1500 & 700 & 35 & 11100 & 1500 & 2000 & 2 \\
\hline $\mathrm{CP} 3$ & 500 & 1500 & 700 & 35 & 11100 & 1500 & 2000 & 3 \\
\hline $\mathrm{CP} 4$ & 500 & 1500 & 700 & 35 & 11100 & 1500 & 2000 & 4 \\
\hline
\end{tabular}




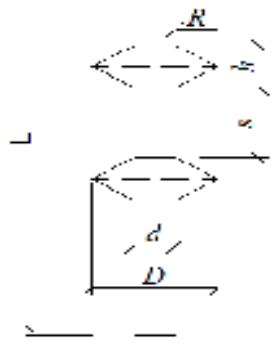

Fig. 1 Calculation model

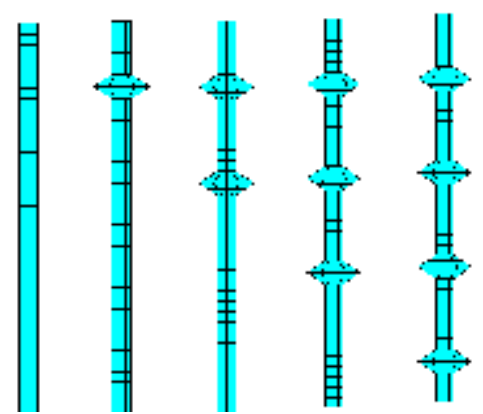

CP0 CP1 CP2 CP3 CP4

Fig. 2 Model pile with different number of expanded-plates

Establishment of Finite Element Model. The pile-soil model established by ANSYS is shown in Fig. 3 (taking two expanded-plates as an example). The mesh generation of pile-soil model follows the principle of proper size and uniform distribution. But in order to better observe the failure state of the soil at the bearing expanded-plate the mesh is encrypted to a certain extent in the special part of the bearing expanded-plate as shown in Fig. 4. (taking expanded-plates 2 as an example). Pile-soil contact pair is used to simulate the contact, sliding and disengagement of the pile-soil model as shown in Fig. 5. (taking two expanded-plates as an example).

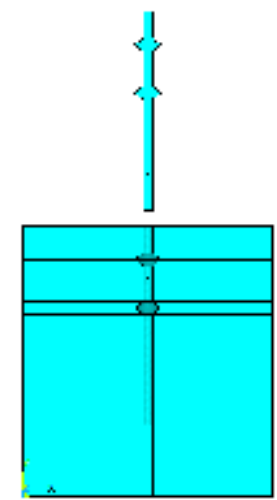

Fig. 4 Mesh generation of pile soil model

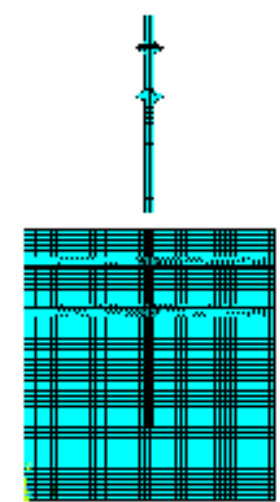

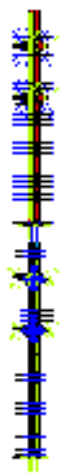

Fig. 5 contact pair
Fig. 3 pile-soil model

Load Method. The pile foundation can be used to bear vertical and horizontal forces. In actual engineering the condition of bearing only vertical or horizontal load is very rare. Generally pile foundations are subjected to horizontal and vertical loads at the same time. For example when the pile foundation bears the weight of the building it must also bear the wind load, earthquake load and so on. Therefore, in order to simulate the actual force of the pile loading method is very important for the simulation. GUO, W, D, et al. studied the influence of lateral movement of upper soil on bending moment of pile and soil reaction force through model tests. It is found that when the pile top has vertical load the maximum deformation, maximum bending moment of the pile and the soil reaction force caused by the lateral movement of the upper soil are less than the situation when the pile top has no vertical load [6].Zheng Gang studied the lateral soil pressure distribution in layered soil under inclined load by nonlinear finite element method. It is pointed out that the vertical component of the inclined load can increase the vertical stress of the soil around the pile and reduce the main stress difference of the soil element around the pile under the horizontal load. Therefore, the strength of the soil can be increased and the lateral displacement of the pile will be reduced [7].

Therefore, in order to simulate the actual situation of the actual pile, the loading method chosen in this model is vertical load. The surface load that is $4.4 \mathrm{MPa}$ is uniformly applied to the top of the pile on the semi-circular. After the vertical load remains stable, the horizontal load is applied and concentrates on the centroid of the semi-section of the pile head. Load from 10KN start and gradually 
increase according to $10 \mathrm{KN}$ loading. Nephogram and curves of the displacement, stress, strain and other parameters are formed. The representative calculation results are chosen for analysis.

Analysis of calculation results of finite element simulation. For the concrete expanded-plate pile which is mainly subjected to horizontal load, the horizontal displacement allowable value of a single pile top is $6 \mathrm{~mm}-10 \mathrm{~mm}$ in the specification [8]. Assuming that the lateral displacement is the control condition of the bearing capacity so when the horizontal displacement at the top of the pile is $10 \mathrm{~mm}$ the corresponding load is the ultimate bearing capacity of the single pile.

Through the finite element simulation of the interaction between concrete expanded-plate pile and soil, the horizontal displacement values of pile top under different loads are extracted from the analysis results of ANSYS models, as shown in Table 3.

Table 3 horizontal displacement of a point on a pile under different loads

\begin{tabular}{c|c|c|c|c|c}
\hline $\begin{array}{c}\text { load } \\
(\mathrm{KN})\end{array}$ & CNP0 & CNP1 & CNP2 & CNP3 & CNP4 \\
\hline 0 & 0 & 0 & 0 & 0 & 0 \\
\hline 10 & $0.30372 \mathrm{E}-0$ & $-0.78749 \mathrm{E}-03$ & $\begin{array}{c}-0.76918 \mathrm{E}-0 \\
3\end{array}$ & $\begin{array}{c}-0.81729 \mathrm{E}-0 \\
3\end{array}$ & $0.50934 \mathrm{E}-03$ \\
\hline 20 & 0.60912 & 0.57595 & 0.57311 & 0.57104 & 0.56931 \\
\hline 30 & 1.244 & 1.1749 & 1.1658 & 1.1592 & 1.1539 \\
\hline 40 & 1.9343 & 1.8182 & 1.801 & 1.784 & 1.7715 \\
\hline 50 & 2.7113 & 2.5386 & 2.5149 & 2.4885 & 2.4689 \\
\hline 60 & 3.6023 & 3.3622 & 3.3375 & 3.3036 & 3.2819 \\
\hline 70 & 4.6392 & 4.3067 & 4.283 & 4.2451 & 4.2225 \\
\hline 80 & 5.8539 & 5.384 & 5.3666 & 5.3264 & 5.304 \\
\hline 90 & 7.2642 & 6.6076 & 6.5898 & 6.5489 & 6.528 \\
\hline 100 & 8.8917 & 7.9824 & 7.9623 & 7.9266 & 7.9046 \\
\hline 110 & 10.747 & 9.5019 & 9.4712 & 9.4416 & 9.4361 \\
\hline
\end{tabular}

It can be seen from the table that for different expanded-plate numbers piles the horizontal displacements of pile top increases gradually with the increase of the horizontal load on the top of the pile. Compared with the straight pile the concrete expanded-plate pile has higher bearing capacity under the same horizontal load. The horizontal displacement of pile top decreases with the number of expanded-plate increases under the same load. In other words the rational setting of the expanded-plate can significantly assist the concrete expanded-plate pile to withstand the horizontal load.

In the finite element analysis the load at the top of the pile is applied and then analyzed. The displacement nephogram of CP0-CP4 pile and soil are extracted from the post-processing of ANSYS , as shown in Fig. 6. The maximum displacement diagram of each model under the same load (110KN) is drew, as shown in Fig. 7. 


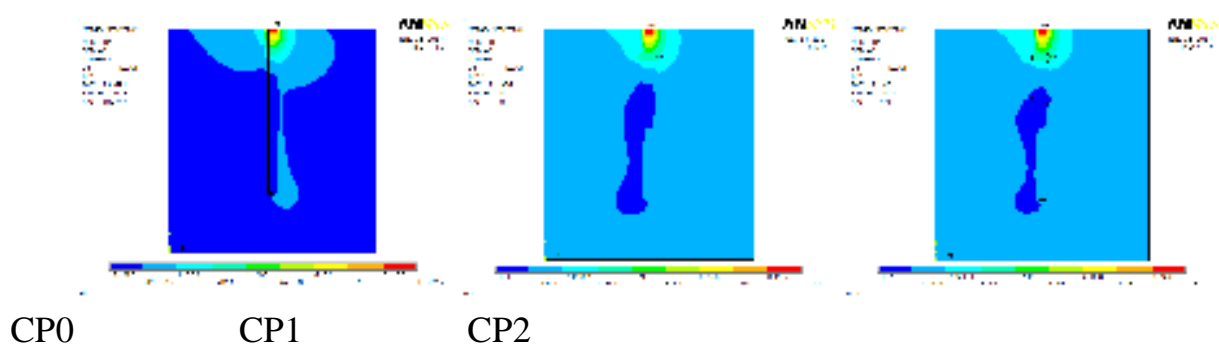

$\mathrm{CP} 3$

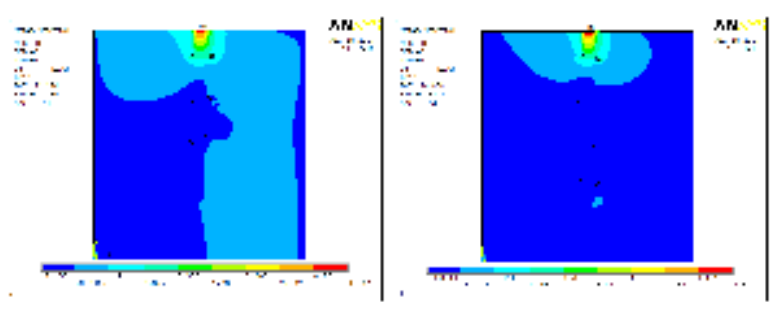

CP4

Fig. 6 displacement nephogram in horizontal direction with different number of expanded-plate

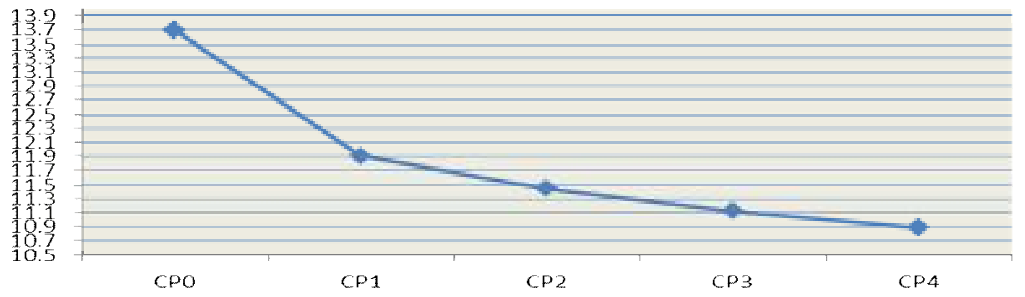

Fig. 7 Maximum horizontal displacement of each model pile under the same load

From the analysis of the above nephogram and the maximum horizontal displacement curve it can be concluded that the influence of expanded-plate on displacement nephogram distribution of the soil around the pile is very significant.

The model is a concrete expanded-plate pile with different number of bearing expanded-plate. Under the same load the maximum horizontal displacement of the piles head are $11.906 \mathrm{~mm}$, $11.451 \mathrm{~mm}, 11.124 \mathrm{~mm}, 10.888 \mathrm{~mm}$ and that of the straight hole pile is $13.694 \mathrm{~mm}$. The bearing capacity increases by $15.02 \%, 19.59 \%, 23.10 \%, 25.77 \%$, respectively. It can be concluded that the horizontal bearing capacity of the concrete expanded-plate pile is higher than that of the straight hole pile under horizontal force and the horizontal bearing capacity of the concrete expanded-plate pile increases gradually with the increase of the number of the expanded-plate. When the number of expanded-plates varies from 1 to 2 the horizontal displacement decreases by $0.0307 \mathrm{~mm}$, decreases $0.0296 \mathrm{~mm}$ from 2 to 3 and decreases $0.0055 \mathrm{~mm}$ from 3 to 4 . That is, when the number of expanded-plate is larger than or equal to 3 the reduction is reduced. Considering the influence factors of concrete expanded-plate pile bearing capacity, if the location of the expanded-plates are chosen properly, the number of expanded-plate is not the more the better. Considering economic and construction convenience the installation of 1-3 bearing expanded-plate can effectively improve the horizontal bearing capacity.

\section{Conclusions}

According to the analysis above the quantity of the expanded-plate is an important parameter for design. Under horizontal load the concrete expanded-plate pile has better horizontal bearing capacity 
than the straight hole pile. Reasonably setting expanded-plate can significantly help the horizontal bearing capacity of concrete expanded pile.

For the concrete expanded-plate pile the number of the bearing expanded-plate has a significant influence on reducing the horizontal displacement of the pile top.The horizontal bearing capacity of concrete expanded-plate pile increases gradually with the increase of the number of expanded-plate。 The vertical load at the top of pile has a significant influence on the horizontal bearing behavior of concrete expanded-plate pile. The existence of vertical load is helpful to reduce horizontal displacement and improve the bearing capacity of concrete expanded-plate pile. For the pile foundation with relatively large load the concrete expanded-plate pile should be adopted. When the location of expanded-plates are chosen properly considering economic and construction convenience the installation of 1-3 bearing expanded-plate can effectively improve the horizontal bearing capacity.

\section{Acknowledgements}

This work is financially supported by National Natural Science Foundation of China (51678275).

\section{References}

[1] Qian Deling. Study on interaction of pile and pile foundation and finite element method [J]. proceedings of the civil engineering society,.2004.

[2] Qian Yongmei, Wang Xihui. Finite element analysis of the influence of the number of plates on the bearing capacity of concrete expanded pile [J]. Shanxi building, 2015.

[3] Qian Yongmei. Study on pile soil effect and ultimate soil bearing capacity of squeezed multi pile [D]. Changchun: Gu Lin University,.2002.

[4] Qian Yongmei, Wang Jie, et al. Working mechanism and research status of concrete expanded pile under horizontal load [J]. Shanxi architecture, 2016.

[5] Mou Nan. Study on the influence of multi plate pile bearing plate parameters on uplift capacity of single pile [D]. Jilin Architecture University thesis, 2014

[6] GUO WD,GHEEEH,Behavior of axially loaded pile groups subjected to lateral soil movement [M]// Foundation Analysis and Design:Innovative Methods,2006.

[7] Zheng Gang, Wang Li. Influence of horizontal and vertical loading levels on the bearing capacity of single pile, Journal of geotechnical engineering, 2008.

[8] JGJ94-2 technical specification for pile foundations of buildings [S]. 